\title{
Investigate the Relation between Psychological Well-being, Self-efficacy and Positive Thinking at Prince Sattam bin Abdul Aziz University Students
}

\author{
Dr. Maha Ahmed Hussein Alkhatib ${ }^{1}$ \\ ${ }^{1}$ Assistant Professor, Educational Psychology (Development), Prince Sattam Bin Abdulaziz University, faculty of \\ education. Aldelam Psychology Department, Saudi Arabia \\ Correspondence: Dr. Maha Ahmed Hussein Alkhatib, Assistant Professor, Educational Psychology (Development), \\ princes Sttam University, faculty of education, Aldelam Psychology Department, Saudi Arabia \\ Received: March 21, 2020 \\ Accepted: May 26, 2020 \\ Online Published: June 1, 2020 \\ doi:10.5430/ijhe.v9n4p138 \\ URL: https://doi.org/10.5430/ijhe.v9n4p138
}

\begin{abstract}
The current study aimed to investigate the relationship between psychological well-being, self-efficacy and positive thinking, among Prince Sattam Bin Abdul Aziz University's students in Saudi Arabia. To answer the study questions, three questionnaires were administrated, two were submitted by the researcher (psychological well-being and self-efficacy), positive thinking scale by (Radi \& Metib, 2017) to 350 university students with range age of 18 to 36 years old. The study adopted a descriptive design to measure the degree of correlation between variables, Results of the study showed that students have moderate psychological well-being level, and that there was a positive relationship between psychological well-being; self-efficacy and positive thinking, also research results indicated that there was a positive relationship between self-efficacy and positive thinking, but the results showed that (gender, faculty, acedamic level) had no impact on psychological well-being or positive thinking. The impact was within (academic level) on self-efficacy in benefit of master degree group.
\end{abstract}

Keywords: psychological well-being, self-efficacy, positive thinking

\section{Introduction}

In any society, Individuals are exposed to too many pressures, such as, psychological, economic and social pressures that may negatively affect their psychological stability As a result, educational institutions such as schools and universities will be faced with challenges In order to avoid this negative affect, Individuals have to work to reduce these effects and achieve a certain level of psychological well-being that helps them to feel stable with their personalities, and enjoy good social relationships with others(Santos et al.,2014). It is also important for them to increase their beliefs in their capabilities or self-efficacy, and to conduct thinking patterns that qualify them and help increase their self-confidence and their ability to control the surrounding environment. In return, these characteristics would pave the way for carrying out daily pressures with confidence and belief in oneself which would tend to lead to improved psychological well-being.

Psychological well-being has strongly influenced positive psychology over the last ten years, due to its prominent position in various societies and cultures, and everyone's pursuit of psychological well-being as a higher goal of life, because of its association with positive mood, satisfaction, happiness, and self- acceptance (İşör, 2016). It can be defined as a structure that includes information related to how an individual evaluates one's self and life (Ryff et al., 1999). Researchers have suggested (Çardak, 2013; Dwiwardani et al., 2014) that psychological well-being includes three main domains:

The first, is at the subjective level which is related to the person who possesses a sense of psychological well-being and contentment with the past, has a meaningful life and happiness with the present, hope and optimism for the future.

The second is at the individual level, this means when a person full of love, courage and high morals, sensitive, tolerant, spiritual, talented, wise whereas.

The third is at the institutional level, it is about a person who is responsible, polite, modest, and has a high professional ethics, so psychological well-being includes self-acceptance, positive relationships with the others, 
autonomy, environmental control, life purpose and personal development, taking into account when dealing with psychological well-being concept, the concept's relationship with emotional, mental,physical,cognitive,personal and social processes(Roothman et al.,2003; Gomez et al.,2018).

This study is focused on university students since they are in an important stage of their lives, stage that they are about to experience career exploration. Research showed that Self-efficacy was strongly related to psychological well-being, and that it plays a pivotal role in protecting children and adolescents in counteracting depressive status (Bandura et al., 1999). Self -efficacy defined by Bandura (1994) as individual's beliefs in their sufficiency to be successful in a task, which directly affects their actions and achievement. He emphasizes that the beliefs of self-efficacy play an important role in changing behavior, due to the effects of such beliefs on the decision-making process to carry out behaviors, effort exerted and deal with problems that may arise during this process (Bandura, 2012).

In addition, (Gregg, 2009) defined self-efficacy as the evaluation of the individual's capabilities, which are relate and interact with the individual's ability to organize one's behavior and learning. The expectations of an individual's self-efficacy are judgments about how the individual behaves in a particular way to reach a goal or adapt effectively to stressful situations,

Researchers have suggested that Self-efficacy belief doesn't depend on personal abilities but the people believe in their abilities, hence in their success. These beliefs affect people's plans and opinions (Zeldin et al., 2008; Santos et al., 2012; Siddiqui, 2015), a study by (Zaker et al., 2016) relating self-efficacy with positive psychology variables, showed that students' self-efficacy can be improved by happiness training, also (Sezgin\& Erdoğan,2018) study showed positive and significant relationships among teacher self-efficacy, humility and forgiveness.

Studies of (Bandura, 1997; Kuijer \& Ridder, 2003; Bisschop et al. ,2004) found that high self- efficacy is related to positive well-being, high self-esteem, better adaptation and stress regulation. Furthermore, high self- efficacy can be the reason for young adult's high activity level and happiness (Cakar, 2012), while people with high degree of self-efficacy can increase their believes in their capability in controlling events in their environment which may increase their psychological well-being, people with low self-efficacy are related to more symptoms of anxiety and depression (Faure \& Loxton, 2003; Kashdan \& Roberts, 2004), as well as to lower levels of psychological well-being (Barlow et al., 2002; Caprara, 2002; Bandura et al. , 2003; Ersöz, 2017; Rasool \&Zubair, 2019)

Another variable that affect psychological well-being is positive thinking, researchers found that in order to reach happiness the individual has to have some abilities such as optimism, hope and a pattern of thinking such as positive thinking which means that the expectation of good events, feeling will be realized by our endeavors and future planning and can Produce stable happiness and purposeful life. (Sligman, 2002).

Positive thinking is one of the patterns of thinking, defined by (Bekhet \& Zauszniewski, 2013) as a mental attitude that makes thoughts occurred in the mind sufficient to become successful, By adopting this pattern of thinking, the individual achieves an inner balance and a better level of awareness that helps to revive life. The effects of positive thinking include positive feelings, emotions, behavioral qualities, and assistance in problem-solving (Naseem \& Khalid, 2010; Bekhet \& Zauszniewski, 2013; Çelik \& Sarıçam ,2018)

Studies showed that positive thoughts can motivate individuals whereas negative thoughts are associated with poor health outcomes and devaluing oneself (Naseem \& Khalid, 2010). In addition, positive thinking linked to increasing mental health, whereas negative thinking can decrease ones' mental health (Tugade \& Fredrickson, 2004).

In reviewing literature, the researcher found a lack of studies within the limits of the researcher's knowledge that dealt with psychological well-being, self-efficacy and positive thinking for Prince Sattam bin Abdul-Aziz University (PSAU) students. This study identifies its problem in answering the following questions

(1) What is the general psychological well-being level among PSAU students?

(2) Are there any significant differences at the level of significance $(\alpha \leq 0.05)$ between the mean of the study sample in positive thinking due to the psychological well-being level?

(3) Are there any significant differences at the level of significance $(\alpha \leq 0.05)$ between the mean of the study sample in self -efficacy due to the level of psychological well-being?

(4) Is there a relationship between psychological well-being, positive thinking and self- efficacy?

(5) Are there any significant differences at the level of significance $(\alpha \leq 0.05)$ between the mean of the study sample in psychological well-being considering the demographic characteristics (gender- faculty- academic level)? 
(6) Are there any significant differences at the level of significance $(\alpha \leq 0.05)$ between the mean of the study sample in self- efficacy considering the demographic characteristics (gender-faculty-academic level)?

(7) Are there any significant differences at the level of significance $(\alpha \leq 0.05)$ between the mean of the study sample in positive thinking considering the demographic characteristics (gender-faculty-academic level)?

The research contributes to the existing knowledge in a way that there are no studies available in the literature which cover these aspects specially for university students in Saudi Arabia. Therefore, the study results will expand knowledge related to the effects of psychological well-being, self-efficacy and positive thinking on university students and how it relates their personal and academic life, and how it contributes in increasing efficiency and achievement.

\section{Literature Review}

Caprara et al. (2006) aimed to examine the concurrent and longitudinal impact of self-efficacy beliefs on subjective well-being in adolescence, namely positive thinking and happiness, a structural model positing adolescents' emotional and interpersonal self-efficacy belief as proximal and distal determinants of positive thinking and happiness has been tested. A sample of 664 Italian adolescents. Results showed that the correlation between self-efficacy beliefs on positive thinking and happiness both concurrent and longitudinal. Also, self-efficacy beliefs manage positive and negative emotions and interpersonal relationships contribute to promote positive expectations about the future, to maintain a high self-concept, to perceive a sense of satisfaction for the life and to experience more positive emotions.

Santos.et.al (2014) aimed to study the relationship of general self-efficacy and subjective well-being among Filipino college students in both private and public institutions. Two scales, General Self-Efficacy Scale (GSES) and Satisfaction with Life Scale (SWLS) were administered on a sample of to 969 college students. The study employed a descriptive-predictive design. Results showed that general self-efficacy and subjective well-being has a positive relationship. Participants with higher levels of general self-efficacy reported higher levels of subjective well-being. Also, the results showed that (age -gender, socio-economic status) had strong impact on general self-efficacy and subjective well-being.

Ghodsbin.et.al (2015) aimed to evaluate the effect of positive thinking training on the level of spiritual well-being among the patients with coronary artery diseases, The sample enrolled 90 patients with confirmed CAD referred to Imam Reza clinic, then they were divided in two groups intervention $(n=45)$ and control groups $(n=45)$. two questionnaires well-being scale (SWBS) and a demographic questionnaire were used. The patients in the intervention group participated in 7 training sessions on positive thinking. Results showed a statistically significant difference between the two groups regarding both variables of time and group $(\mathrm{P}<0.001)$. SWB is an important factor which should be considered in the treatment process, and nurses could maintain and improve such dimension of health in the patients through their intervention including drawing the patients' attention to optimism and positive thinking

Siddiqui (2015) investigated the impact of Self-efficacy on Psychological Well-being among undergraduate students. The sample consisted of 100 (50 Male and 50 Female) University students. General Self-Efficacy Scale; Psychological Well-being was used. The results showed that there was insignificant difference between Male and Female students Self-efficacy, but an insignificant difference was found in Psychological well-being with both groups.

Ersöz (2017) amid to examine the relationship between exercise and general self-efficacy, depression, and psychological well-being of college students. A male and female sample of 522 university students was used, The General Self-Efficacy Scale (GSES), Beck Depression Inventory (BDI), Physical Activity Stages of Change Questionnaire (PASCQ), and "Psychological Well-Being Scale (PWBS) were conduct. Results showed that significant disparities have been found between the sample' level of self-efficacy, depression, and psychological well-being, the sample' general self-efficacy and psychological well-being levels were high and the depression levels were low when on advanced levels of exercise.

Tommasi.et.al (2018) aimed to study Correlations Between Personality, Affective and Filial Self-Efficacy Beliefs, and Psychological Well-Being in a Sample of Italian Adolescents. A sample of 179 Italian adolescents were conducted. Eysenck Personality scale, adolescent perceived Self-efficacy belief of positive and negative emotions Scale, Psychological Well-being scale were used. Results show that extraversion, neuroticism, and self-efficacy beliefs in emotion regulation are correlated with psychological well-being, while filial self-efficacy does not. There were no significant effects of Self-efficacy beliefs on personality traits, but results showed that self -efficacy beliefs in expressing positive emotions reduce negative characteristics of individuals with high level of psychoticism. 
Yuksel (2019) amid to study the perceived levels of self-efficacy, psychological well-being, and social support in pregnant women. Using cross-sectional and descriptive, on a sample consists of 258 pregnant women. Self-efficacy Scale, Psychological Well-being, and Multidimensional Scale of Perceived Social Support Scale were used to collect data. Results: found that factors like age, educational level, presence of the social support and having birth knowledge were affecting the self-efficacy, perceived social support and psychological well-being levels of the pregnant women $(\mathrm{p}<.05)$.There were statistically significant relationships between self-efficacy, psychological well-being and perceived social support in pregnant women.

Fernández.et.al (2019) aimed to study the relationship between psychological well-being, self-efficacy and self-esteem in non-dependent individuals over the age of 60. The sample included 148 seniors between 60 and 96 years of age. autonomy and physical and social activity scale, self-efficacy for aging scale, self-esteem scale, and the Spanish version of the wellness psychology scale were used. The results suggest that psychological well-being was not associated with age, but with a set of psychological factors. Psychological well-being was associated with health perception, physical and sports activities, also the results showed self-efficacy and self-esteem are considered promoters of physical, psychological and social well-being, also the study found that encouraging older people in physical and sports, recreational, social and cognitive activities promoting wellness and, ultimately, active aging

The literature review suggests both types of qualitative and quantitative research approaches as well as descriptive and exploratory research designs. Likewise, the psychological well-being has an effect on both self-efficacy and positive thinking, but one study aimed to trace the relationship between psychological well-being, self-efficacy and positive thinking. The current study is similar to previous studies on using descriptive research design and the sample used in some studies, and differs in the investigating the relationship between all three variables for the first time in a Saudi Arabia university, the study was conducted in the first university semester (2019-2020)

\section{Methods}

\subsection{Study Method}

The study adopted to achieve its objectives through descriptive research, the three questionnaires were conducted electronically for all members of the study sample, Data were collected and analyzed using SPSS 18.0 program, to determine the relationships among the means of psychological well-being general self-efficacy, and positive thinking scores, Statistical significance level was considered as $(\alpha \leq 0.05)$.

\subsection{Population}

The population of the study consisted of all students at PSAU- Saudi Arabia.

\subsection{Study Sample}

A sample of 350 university students, were randomly chosen both male and female, from applied science and humanity college, studying in bachelor or master degree academic level, Before the study, approval to research with human participants was obtained from the university's ethical committee.

The following Table 1 shows the distribution of the study sample according to the demographic variables

Table 1. distribution of participant according to demographic variables

\begin{tabular}{ccc}
\hline demographic Variables & $N$ & $\%$ \\
\hline Gender & & \\
Male & 73 & $21 \%$ \\
Female & 277 & $79 \%$ \\
Faculty & & \\
humanity & 190 & $54 \%$ \\
Applied sciences & 160 & $46 \%$ \\
Academic stage & & \\
bachelor & 294 & $84 \%$ \\
master & 56 & $16 \%$ \\
\hline
\end{tabular}




\subsection{Study Tools}

Three questionnaires were used "Psychological Well-Being (PWBS), "General Self-Efficacy," which were constructed by the researcher, and "Standardized positive thinking questionnaire" for Saudi Arabia environment, details were given below:

\subsubsection{Psychological Well-Being Questionnaire (PWBS).}

The PWBS is a 38-item questionnaire which was derived from the PWBS (Ryff \& singer,2008), the Saudi PWBS questionnaire (alhazmi,2017) and validated for the purpose of measuring PWB FOR Saudi Arabia university students. The PWBS consists of six subscales including (autonomy, environmental mastery, positive relationship, the purpose of life, self-acceptance, personal growth); each of which has $(7 ; 6 ; 5,6 ; 6 ; 8)$ items. Each item is rated on a five-point Likert scale ranging from 1 (None) to 5 (very high). A total score ranges from (190 to 38). Cronbach's coefficient alpha for the questionnaire in general, was tested in a sample of 100 participants (65 females, 35 males). The Cronbach's alphas for all participants was (0.85). This score indicates good internal consistency for the PWBS. Test-retest reliability of the PWBS was calculated at four weeks interval. The coefficient of the whole participants was (0.87), respectively. All correlation coefficients were significant at $\mathrm{p}<.001$. These scores indicate adequate test-retest reliability of the PWBS. Factor analysis identified that confirmed by the PWBS (alhazmi,2017).

\subsubsection{General Self-Efficacy Questionnaire (GSE)}

The GSE is a 28 -item questionnaire which was derived from previous Arabic literature considering self -efficacy (Aljaser,2007; Abo-salama,2014) questionnaires, The GSE consists of four subscales including (initiative; effort exerted; perseverance; effectiveness), each of which has (7) items. Each item is rated on a three-point Likert scale ranging from 1 (disagree) to 3 (agree). A total score ranges from (84 to 28). Cronbach's coefficient alpha for the questionnaire in general, was tested in a sample of 100 participants. The Cronbach's alphas for all participants was (0.845). This score indicates good internal consistency for the GSE. Test-retest reliability of the GSE was calculated at four weeks interval. The coefficient of the whole participants was $(0.83)$, respectively. All correlation coefficients were significant at $\mathrm{p}<.001$. These scores indicate adequate test-retest reliability of the GSE.

\subsubsection{Standardized Positive Thinking Questionnaire (SPTH):}

The SPTH (Radi \& metib, 2017) is a 28 -item questionnaire that has been developed for the Saudi Arabia university students. Each item is rated on a 3-point Likert-type scale that ranges from 1 (disagree) to 3 (agree). The SPTH has demonstrated good psychometric properties (Radi \& metib, 2017). Alpha coefficients of Saudi Arabia version of the SPTH total score were 0.83 and 0.91 for a sample of Saudi Arabia students, Test-retest reliability of the SPTH confirmed with coefficients of 0.84, respectively, Cronbach's alpha coefficient for the SPTH total score was 0.83 for the present study.

Table 2. Reliability coefficient values for internal consistency and test-retest of study variables

\begin{tabular}{cccc}
\hline no & questionnaire & $\begin{array}{c}\text { Cronbach's alpha internal } \\
\text { consistency coefficient }\end{array}$ & $\begin{array}{c}\text { Pearson correlation } \\
\text { coefficient }\end{array}$ \\
\hline 1 & Psychological Well-Being & 0.85 & 0.87 \\
2 & General Self-Efficacy & 0.845 & 0.83 \\
3 & positive thinking & 0.83 & 0.84 \\
\hline
\end{tabular}

\section{Results and Discussion}

1- What is the general psychological well-being level among prince PSAU students?

The results of the Table 3 indicate that the Means and standard deviation of psychological well-being scores of participants. 
Table 3. Means and Standard Deviations for psychological well-being scores of participants

\begin{tabular}{|c|c|c|c|c|c|c|c|}
\hline Item & $N$ & Minimum & Maximum & Mean & $\begin{array}{c}\text { Std. } \\
\text { Deviation }\end{array}$ & $\begin{array}{c}\text { Item } \\
\text { arrangement }\end{array}$ & $\begin{array}{c}\text { degree of } \\
\text { use }\end{array}$ \\
\hline $\mathrm{R} 1$ & 350 & 1 & 5 & 3.69 & .897 & 28 & Medium \\
\hline $\mathrm{R} 2$ & 350 & 2 & 5 & 3.94 & .911 & 16 & High \\
\hline R3 & 350 & 1 & 5 & 3.98 & .951 & 13 & High \\
\hline R4 & 350 & 1 & 5 & 4.15 & .869 & 6 & High \\
\hline R5 & 350 & 1 & 5 & 3.91 & .942 & 18 & High \\
\hline R6 & 350 & 1 & 5 & 2.79 & 1.213 & 30 & Medium \\
\hline R7 & 350 & 1 & 5 & 3.77 & .968 & 26 & High \\
\hline $\mathrm{R} 8$ & 350 & 1 & 5 & 3.89 & .903 & 22 & High \\
\hline R9 & 350 & 1 & 5 & 3.45 & 1.066 & 29 & Medium \\
\hline R10 & 350 & 1 & 5 & 3.86 & .919 & 23 & High \\
\hline R11 & 350 & 1 & 5 & 2.76 & 1.155 & 32 & Medium \\
\hline $\mathrm{R} 12$ & 350 & 1 & 5 & 2.79 & 1.138 & 31 & Medium \\
\hline $\mathrm{R} 13$ & 350 & 1 & 5 & 4.32 & .877 & 1 & High \\
\hline R14 & 350 & 1 & 5 & 4.23 & .875 & 3 & High \\
\hline R15 & 350 & 1 & 5 & 3.90 & .993 & 21 & High \\
\hline R16 & 350 & 1 & 5 & 3.90 & .999 & 20 & High \\
\hline R17 & 350 & 1 & 5 & 2.37 & 1.277 & 35 & Medium \\
\hline $\mathrm{R} 18$ & 350 & 1 & 5 & 3.96 & .875 & 14 & High \\
\hline R19 & 350 & 1 & 5 & 4.14 & .952 & 7 & High \\
\hline R20 & 350 & 1 & 5 & 4.00 & .883 & 12 & High \\
\hline $\mathrm{R} 21$ & 350 & 1 & 5 & 3.96 & 1.027 & 15 & High \\
\hline $\mathrm{R} 22$ & 350 & 1 & 5 & 4.10 & .911 & 9 & High \\
\hline $\mathrm{R} 23$ & 350 & 1 & 5 & 3.93 & .915 & 17 & High \\
\hline R24 & 350 & 1 & 5 & 2.32 & 1.225 & 36 & Medium \\
\hline $\mathrm{R} 25$ & 350 & 1 & 5 & 3.79 & .967 & 25 & High \\
\hline R26 & 350 & 1 & 5 & 4.18 & .924 & 5 & High \\
\hline R27 & 350 & 1 & 5 & 3.76 & .992 & 27 & High \\
\hline $\mathrm{R} 28$ & 350 & 1 & 5 & 4.08 & 1.047 & 10 & High \\
\hline R29 & 350 & 1 & 5 & 2.09 & 1.199 & 37 & Low \\
\hline R30 & 350 & 1 & 5 & 3.85 & 1.000 & 24 & High \\
\hline R31 & 350 & 1 & 5 & 3.91 & 1.125 & 19 & High \\
\hline R32 & 350 & 1 & 5 & 4.25 & .859 & 2 & High \\
\hline R33 & 350 & 1 & 5 & 2.03 & 1.194 & 38 & Low \\
\hline R34 & 350 & 1 & 5 & 2.66 & 1.245 & 34 & Medium \\
\hline R35 & 350 & 1 & 5 & 4.11 & .965 & 8 & High \\
\hline R36 & 350 & 1 & 5 & 2.67 & 1.102 & 33 & Medium \\
\hline R37 & 350 & 2 & 5 & 4.07 & .904 & 11 & High \\
\hline R38 & 350 & 1 & 5 & 4.22 & .936 & 4 & High \\
\hline $\begin{array}{l}\text { Psychological } \\
\text { well-being } \\
\text {-total }\end{array}$ & 350 & & & 137.74 & 13.094 & & \\
\hline $\begin{array}{l}\text { Valid N (list } \\
\text { wise) }\end{array}$ & 350 & & & & & & \\
\hline
\end{tabular}


As shown in Table 3 total mean of the participants answers to the paragraphs that measure the PWB has reached (137.74) and represents an average grade, paragraph (13)came first (I enjoy talking to my friends and family), Paragraph (32) (new experiences helps in self-improvement), and in the last place came paragraph (33),(I have no desire in self -development) and all paragraphs that measure that area was promoted low ratings and medium and high.

2-Are there any significant differences at the level of significance $(\alpha \leq 0.05)$ between the mean of the study sample in positive thinking due to the psychological well-being level?

The results of the Table 4 indicate the Means and standard deviation of positive thinking due to the well-being levels.

Table 4. Means and Standard Deviations for positive thinking due to(PWBS) scores

\begin{tabular}{ccccccc}
\hline & $\begin{array}{l}\text { Well-being } \\
\text { psy }\end{array}$ & sections & & & & \multicolumn{2}{l}{$\begin{array}{l}\text { Std. } \\
\text { Error } \\
\text { Sean }\end{array}$} \\
\hline total & & $N$ & Mean & $\begin{array}{l}\text { Deviation } \\
\text { Mean }\end{array}$ \\
thinking & 2.00 & 197 & 67.25 & 7.416 & .528 \\
& 3.00 & 153 & 72.57 & 8.240 & .666
\end{tabular}

It is clear from the results shown Table 4 that there was a significant difference in positive thinking between level 1 $(\mathrm{M}=67.25, \mathrm{SD}=7.416)$, level2 $(\mathrm{M}=72.57, \mathrm{SD}=8.240)$, $\mathrm{t}$-test was conducted to check the difference.

Table 5. t-test for positive thinking due to PWB

\begin{tabular}{|c|c|c|c|c|c|c|c|c|c|c|}
\hline & & \multicolumn{2}{|c|}{$\begin{array}{c}\text { Levene's Test } \\
\text { for Equality of } \\
\text { Variances }\end{array}$} & \multicolumn{7}{|c|}{ t-test for Equality of Means } \\
\hline & & \multirow[t]{2}{*}{$F$} & \multirow[t]{2}{*}{ Sig. } & \multirow[t]{2}{*}{$t$} & \multirow[t]{2}{*}{$d f$} & \multirow{2}{*}{$\begin{array}{c}\text { Sig. } \\
\text { (2-taile } \\
\text { d) }\end{array}$} & \multirow[t]{2}{*}{$\begin{array}{c}\text { Mean } \\
\text { Difference }\end{array}$} & \multirow[t]{2}{*}{$\begin{array}{l}\text { Std. Error } \\
\text { Difference }\end{array}$} & \multicolumn{2}{|c|}{$\begin{array}{l}\text { 95\% Confidence Interva } \\
\text { of the Difference }\end{array}$} \\
\hline & & & & & & & & & Lower & Upper \\
\hline \multirow[t]{2}{*}{$\begin{array}{l}\text { total } \\
\text { thinking }\end{array}$} & $\begin{array}{c}\text { Equal } \\
\text { variances } \\
\text { assumed }\end{array}$ & 1.319 & .252 & 6.340 & 348 & .000 & -5.320 & .839 & -6.970 & -3.670 \\
\hline & $\begin{array}{c}\text { Equal } \\
\text { variances } \\
\text { not } \\
\text { assumed }\end{array}$ & & & 6.257 & 308.685 & .000 & -5.320 & .850 & -6.993 & -3.647 \\
\hline
\end{tabular}

* Statistically significant at the level of significance $(\alpha \leq 0.05)$.

As shown in Table 5 there were significant differences in the scores between the two levels of psychological well-being on positive thinking ( $\mathrm{t}(348)=6.34, \mathrm{P}=000$, on $(\alpha=0.05)$.

These results suggest that the level of psychological well-being does affect positive thinking; specifically, our results suggest that when the level of psychological well-being increases positive thinking increase.

3 -Are there any significant differences at the level of significance $(\alpha \leq 0.05)$ between the mean of the study sample in self -efficacy due to the level of psychological well-being?

The results of the Table 6 indicate the Means and standard deviation of self -efficacy due to the well-being levels.

Table 6. Means and Standard Deviations for in self -efficacy due to (PWBS)

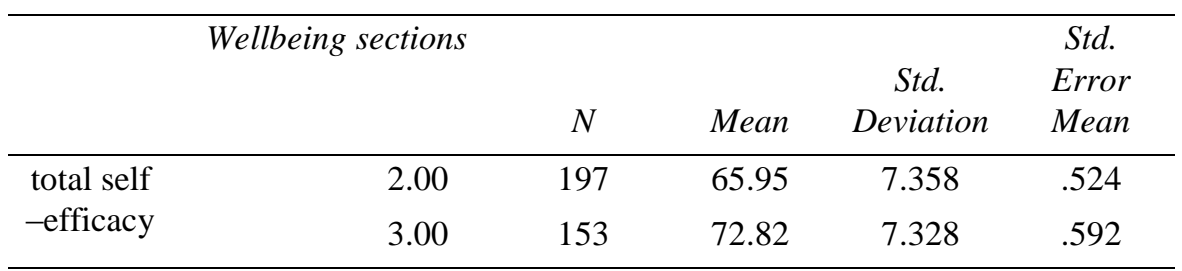

It is clear from the results shown in Table 6 that there were significant differences in the scores between the two levels of psychological well-being on self -efficacy between level $1(\mathrm{M}=65.95, \mathrm{SD}=7.358)$,level $2(\mathrm{M}=72.82$, $\mathrm{SD}=7.328$ ), $\mathrm{t}$-test was conducted. 
Table 7. t-test for self -efficacy

\begin{tabular}{|c|c|c|c|c|c|c|c|c|c|c|}
\hline & & \multicolumn{2}{|c|}{$\begin{array}{c}\text { Levene's Test for } \\
\text { Equality of } \\
\text { Variances }\end{array}$} & \multicolumn{7}{|c|}{ t-test for Equality of Means } \\
\hline & & \multirow[t]{2}{*}{$F$} & \multirow[t]{2}{*}{ Sig. } & \multirow[t]{2}{*}{$t$} & \multirow[t]{2}{*}{$d f$} & \multirow[t]{2}{*}{$\begin{array}{c}\text { Sig. } \\
\text { (2-tailed } \\
\text { ) }\end{array}$} & \multirow[t]{2}{*}{$\begin{array}{c}\text { Mean } \\
\text { Difference }\end{array}$} & \multirow[t]{2}{*}{$\begin{array}{l}\text { Std. Error } \\
\text { Difference }\end{array}$} & \multicolumn{2}{|c|}{$\begin{array}{c}\text { 95\% Confidence } \\
\text { Interval of the } \\
\text { Difference }\end{array}$} \\
\hline & & & & & & & & & Lower & Upper \\
\hline \multirow[t]{2}{*}{$\begin{array}{l}\text { Total } \\
\text { efficacy }\end{array}$} & $\begin{array}{c}\text { Equal } \\
\text { variances } \\
\text { assumed }\end{array}$ & .079 & .779 & 8.670 & 348 & .000 & -6.863 & .792 & -8.419 & -5.306 \\
\hline & $\begin{array}{c}\text { Equal } \\
\text { variances } \\
\text { not assumed }\end{array}$ & & & -8.675 & 327.512 & .000 & -6.863 & .791 & -8.419 & -5.306 \\
\hline
\end{tabular}

* Statistically significant at the level of significance $(\alpha \leq 0.05)$.

As shown in Table 7 there were significant differences in the scores between the two levels of psychological well-being on self -efficacy $(\mathrm{t}(348)=8.67, \mathrm{P}=000)$.

These results suggest that the level of psychological well-being does have an effect on self -efficacy, specifically our results suggest that when the level of psychological well-being increases self -efficacy increase.

4- Is there a relationship between psychological well-being, positive thinking and self- efficacy?

The results of the Table 8 indicate A person product-moment correlation coefficient to assess the relationship between well-being, self-efficacy and positive thinking

Table 8. Person correlation for well-being, self-efficacy and positive thinking

\begin{tabular}{ccccc}
\hline & & Total psychological & & \\
& & wellbeing & Total efficacy & Total thinking \\
\hline \multirow{2}{*}{$\begin{array}{c}\text { Total psychological } \\
\text { wellbeing }\end{array}$} & Pearson Correlation & 1 & $.525^{* *}$ & $.417^{* *}$ \\
& Sig. (2-tailed) & & .000 & .000 \\
& $\mathrm{~N}$ & 350 & 350 & 350 \\
Total efficacy & Pearson Correlation & $.525^{* *}$ & 1 & $.594^{* *}$ \\
& Sig. (2-tailed) & .000 & & .000 \\
& $\mathrm{~N}$ & 350 & 350 & 350 \\
Total thinking & Pearson Correlation & $.417^{* *}$ & $.594^{* *}$ & 1 \\
**. Correlation is significant at the 0.01 level (2-tailed). & & .000 & \\
\hline
\end{tabular}

The results shown in Table 8 indicates that there was a positive correlation between psychological well- being and self- efficacy ( $\mathrm{r}=0.525, \mathrm{~N}=350)$, between psychological well- being and positive thinking $(\mathrm{r}=0.417, \mathrm{~N}=350)$, and between self- efficacy and positive thinking $(\mathrm{r}=0.594,0.417)$. Results overall. Showed that psychological well- being increases when self- efficacy and positive thinking increases, also self- efficacy was increases when positive thinking increases.

5-Are there any significant differences at the level of significance $(\alpha \leq 0.05)$ between the mean of the study sample in psychological well-being considering the demographic characteristics (gender- faculty- academic level)?

To answer this question, mean and the standard deviation was presented to the demographic variables (gender, faculty academic level) 
Table 9. Means and Standard Deviations

\begin{tabular}{|c|c|c|c|c|c|c|}
\hline gender & faculty & \multicolumn{2}{|c|}{ Grade level } & Mean & Std. Deviation & $N$ \\
\hline \multirow[t]{9}{*}{ male } & applied & \multirow{3}{*}{ dimension3 } & bacalore & 136.29 & 10.291 & 7 \\
\hline & & & master & 133.00 & 6.094 & 8 \\
\hline & & & Total & 134.53 & 8.175 & 15 \\
\hline & humanities & \multirow{3}{*}{ dimension3 } & 1 & 138.95 & 12.448 & 19 \\
\hline & & & 2 & 139.49 & 15.292 & 39 \\
\hline & & & Total & 139.31 & 14.314 & 58 \\
\hline & Total & \multirow{3}{*}{ dimension3 } & 1 & 138.23 & 11.765 & 26 \\
\hline & & & 2 & 138.38 & 14.314 & 47 \\
\hline & & & Total & 138.33 & 13.378 & 73 \\
\hline \multirow[t]{9}{*}{ female } & 1 & \multirow{3}{*}{ dimension3 } & 1 & 138.21 & 12.138 & 168 \\
\hline & & & 2 & 141.71 & 23.697 & 7 \\
\hline & & & Total & 138.35 & 12.699 & 175 \\
\hline & 2 & \multirow{3}{*}{ dimension3 } & 1 & 136.17 & 13.680 & 100 \\
\hline & & & 2 & 141.50 & .707 & 2 \\
\hline & & & Total & 136.27 & 13.565 & 102 \\
\hline & Total & \multirow{3}{*}{ dimension3 } & 1 & 137.45 & 12.749 & 268 \\
\hline & & & 2 & 141.67 & 20.524 & 9 \\
\hline & & & Total & 137.59 & 13.039 & 277 \\
\hline \multirow[t]{9}{*}{ Total } & 1 & \multirow{3}{*}{ dimension3 } & 1 & 138.14 & 12.050 & 175 \\
\hline & & & 2 & 137.07 & 16.718 & 15 \\
\hline & & & Total & 138.05 & 12.429 & 190 \\
\hline & 2 & \multirow{3}{*}{ dimension3 } & 1 & 136.61 & 13.479 & 119 \\
\hline & & & 2 & 139.59 & 14.911 & 41 \\
\hline & & & Total & 137.38 & 13.874 & 160 \\
\hline & Total & \multirow{3}{*}{ dimension3 } & 1 & 137.52 & 12.648 & 294 \\
\hline & & & 2 & 138.91 & 15.301 & 56 \\
\hline & & & Total & 137.74 & 13.094 & 350 \\
\hline
\end{tabular}

As shown in Table 9 there are obvious differences between the mean values of the responses of the sample according to the three demographic variables.

A one- way between subjects' ANOVA, was conducted to compare the effect of psychological well- being on demographic variables.

Table 10. a one -way ANOVA for demographic variables in psychological well-being

\begin{tabular}{cccccc}
\hline Source & $\begin{array}{c}\text { Type III Sum of } \\
\text { Squares }\end{array}$ & Df & Mean Square & $F$ & Sig. \\
\hline Corrected Model & $764.413 \mathrm{a}$ & 7 & 109.202 & .632 & .729 \\
Intercept & 1215724.929 & 1 & 1215724.929 & 7038.203 & .000 \\
Gender & 97.101 & 1 & 97.101 & .562 & .454 \\
Faculty & 47.242 & 1 & 47.242 & .274 & .601 \\
grade level & 36.834 & 1 & 36.834 & .213 & .645 \\
Error & 59074.444 & 342 & 172.732 & & \\
Total & 6700422.000 & 350 & & & \\
Corrected Total & 59838.857 & 349 & & & \\
\hline
\end{tabular}

a. R Squared $=.013$ (Adjusted R Squared $=-.007$ ) 
As shown in Table 10 there are no statistically significant differences between the mean values according to the gender variable $\mathrm{F}(7,1)=0.562 \mathrm{P}=0.454$, also, there are no statistically significant differences between the mean values according to the faculty variable $\mathrm{F}(7,1)=0.274, \mathrm{P}=0.601$, and there are no statistically significant differences between the mean values according to the academic level variable $F(7,1)=0.213, P=0.645$. depending on the significance of the calculated values of $(F)$ shown in the previous table at the significance level $(\alpha \leq 0.05)$

6-Are there any significant differences at the level of significance $(\alpha \leq 0.05)$ between the mean of the study sample in self- efficacy considering the demographic characteristics (gender - faculty - academic level)?

To answer this question, mean and the standard deviation was presented to the demographic variables (gender, faculty academic level)

Table 11. Means and Standard Deviations

\begin{tabular}{|c|c|c|c|c|c|c|}
\hline \multirow{2}{*}{$\begin{array}{c}\text { gender } \\
\text { male }\end{array}$} & \multirow{2}{*}{$\begin{array}{c}\text { faculty } \\
\text { applied }\end{array}$} & \multicolumn{2}{|c|}{ academic level } & \multirow{2}{*}{$\begin{array}{l}\text { Mean } \\
65.86\end{array}$} & \multirow{2}{*}{$\begin{array}{c}\text { Std. Deviation } \\
4.981\end{array}$} & \multirow{2}{*}{$\begin{array}{l}N \\
7\end{array}$} \\
\hline & & dimension3 & bacalore & & & \\
\hline & & & master & 73.38 & 5.097 & 8 \\
\hline & & & Total & 69.87 & 6.221 & 15 \\
\hline & humanities & dimension3 & bacalore & 68.00 & 8.273 & 19 \\
\hline & & & master & 68.05 & 7.455 & 39 \\
\hline & & & Total & 68.03 & 7.659 & 58 \\
\hline & Total & dimension3 & bacalore & 67.42 & 7.495 & 26 \\
\hline & & & master & 68.96 & 7.345 & 47 \\
\hline & & & Total & 68.41 & 7.384 & 73 \\
\hline \multirow[t]{9}{*}{ female } & applied & dimension3 & bacalore & 70.15 & 7.747 & 168 \\
\hline & & & master & 69.86 & 11.172 & 7 \\
\hline & & & Total & 70.14 & 7.868 & 175 \\
\hline & humanities & dimension3 & bacalore & 67.10 & 8.617 & 100 \\
\hline & & & master & 77.50 & 4.950 & 2 \\
\hline & & & Total & 67.30 & 8.667 & 102 \\
\hline & Total & dimension3 & bacalore & 69.01 & 8.201 & 268 \\
\hline & & & master & 71.56 & 10.394 & 9 \\
\hline & & & Total & 69.10 & 8.270 & 277 \\
\hline \multirow[t]{9}{*}{ Total } & applied & dimension3 & bacalore & 69.98 & 7.692 & 175 \\
\hline & & & master & 71.73 & 8.353 & 15 \\
\hline & & & Total & 70.12 & 7.737 & 190 \\
\hline & humanities & dimension3 & bacalore & 67.24 & 8.535 & 119 \\
\hline & & & master & 68.51 & 7.593 & 41 \\
\hline & & & Total & 67.57 & 8.299 & 160 \\
\hline & Total & dimension3 & bacalore & 68.87 & 8.142 & 294 \\
\hline & & & master & 69.37 & 7.859 & 56 \\
\hline & & & Total & 68.95 & 8.088 & 350 \\
\hline
\end{tabular}

As shown in Table 11 there were obvious differences between the mean values of the responses of the sample according to the three demographic variables.A one- way between subjects' ANOVA, that was conducted to compare the effect of demographic variables. 
Table 12. one -way ANOVA for demographic variables in self- efficacy

\begin{tabular}{cccccc}
\hline Source & $\begin{array}{c}\text { Type III Sum of } \\
\text { Squares }\end{array}$ & $d f$ & Mean Square & $F$ & Sig. \\
\hline Corrected Model & $1010.306 \mathrm{a}$ & 7 & 144.329 & 2.262 & .029 \\
Intercept & 311942.014 & 1 & 311942.014 & 4889.068 & .000 \\
gender & 86.593 & 1 & 86.593 & 1.357 & .245 \\
faculty & 1.971 & 1 & 1.971 & .031 & .861 \\
academic level & 310.748 & 1 & 310.748 & 4.870 & .028 \\
Error & 21820.963 & 342 & 63.804 & & \\
Total & 1686974.000 & 350 & & & \\
Corrected Total & 22831.269 & 349 & & & \\
\hline
\end{tabular}

a. R Squared $=.044$ (Adjusted R Squared $=.025$ )

As shown Table 12 there were a no statistically significant differences between the mean values according to the gender variable $\mathrm{F}(7,1)=1.357, \mathrm{P}=0.245$, there was no statistically significant differences between the mean values according to the faculty variable $\mathrm{F}(7,1)=0.031, \mathrm{P}=0.861$, but there was statistically significant differences between the mean values according to the academic level variable $\mathrm{F}(7,1)=4.870, \mathrm{P}=0.028$. depending on the significance of the calculated values of $(F)$ shown in the previous table at the significance level $(\alpha \leq 0.05)$

7 - Are there any significant differences at the level of significance $(\alpha \leq 0.05)$ between the mean of the study sample in positive thinking considering the demographic characteristics (gender - faculty - academic level)?

To answer this question, mean and the standard deviation was presented to the demographic variables (gender, faculty academic level)

Table13. Means and Standard Deviations

\begin{tabular}{|c|c|c|c|c|c|c|}
\hline gender & faculty & Gra & & Mean & Std. Deviation & $N$ \\
\hline \multirow{9}{*}{ male } & \multirow{3}{*}{ applied } & \multirow{3}{*}{ dimension3 } & bacalore & 64.43 & 6.949 & 7 \\
\hline & & & maste & 72.88 & 5.963 & 8 \\
\hline & & & Total & 68.93 & 7.583 & 15 \\
\hline & \multirow{3}{*}{ humanities } & \multirow{3}{*}{ dimension 3} & bacalore & 67.47 & 7.677 & 19 \\
\hline & & & master & 67.05 & 7.800 & 39 \\
\hline & & & Total & 67.19 & 7.695 & 58 \\
\hline & \multirow{3}{*}{ Total } & \multirow{3}{*}{ dimension3 } & bacalore & 66.65 & 7.478 & 26 \\
\hline & & & master & 68.04 & 7.782 & 47 \\
\hline & & & Total & 67.55 & 7.652 & 73 \\
\hline \multirow{9}{*}{ female } & \multirow{3}{*}{ applied } & \multirow{3}{*}{ dimension3 } & bacalore & 70.97 & 8.082 & 168 \\
\hline & & & & 70.57 & 10.438 & 7 \\
\hline & & & Total & 70.95 & 8.152 & 175 \\
\hline & \multirow{3}{*}{ humanities } & \multirow{3}{*}{ dimension3 } & bacalore & 68.52 & 8.374 & 100 \\
\hline & & & master & 75.50 & .707 & 2 \\
\hline & & & Total & 68.66 & 8.348 & 102 \\
\hline & \multirow{3}{*}{ Total } & \multirow{3}{*}{ dimension3 } & bacalore & 70.06 & 8.263 & 268 \\
\hline & & & master & 71.67 & 9.301 & 9 \\
\hline & & & Total & 70.11 & 8.285 & 277 \\
\hline \multirow{9}{*}{ Total } & \multirow{3}{*}{ applied } & \multirow{3}{*}{ dimension3 } & bacalore & 70.71 & 8.125 & 175 \\
\hline & & & master & 71.80 & 8.117 & 15 \\
\hline & & & Total & 70.79 & 8.108 & 190 \\
\hline & \multirow{3}{*}{ humanities } & \multirow{3}{*}{ dimension3 } & bacalore & 68.35 & 8.245 & 119 \\
\hline & & & master & 67.46 & 7.823 & 41 \\
\hline & & & Total & 68.13 & 8.124 & 160 \\
\hline & \multirow{3}{*}{ Total } & \multirow{3}{*}{ dimension3 } & bacalore & 69.76 & 8.241 & 294 \\
\hline & & & master & 68.62 & 8.065 & 56 \\
\hline & & & Total & 69.57 & 8.212 & 350 \\
\hline
\end{tabular}


As shown in Table 13 there are obvious differences between the mean values of the responses of the sample according to the three demographic variables.

A one- way between subjects' ANOVA, was presented to the demographic variables (gender, faculty, academic level)

Table14. one -way ANOVA for demographic variables in positive thinking

\begin{tabular}{cccccc}
\hline Source & $\begin{array}{c}\text { Type III Sum } \\
\text { of Squares }\end{array}$ & $d f$ & Mean Square & $F$ & Sig. \\
\hline Corrected Model & $1120.320 \mathrm{a}$ & 7 & 160.046 & 2.442 & .019 \\
Intercept & 309156.830 & 1 & 309156.830 & 4716.530 & .000 \\
gender & 187.672 & 1 & 187.672 & 2.863 & .092 \\
Ifaculty & .090 & 1 & .090 & .001 & .971 \\
Grade level & 212.264 & 1 & 212.264 & 3.238 & .073 \\
Error & 22417.249 & 342 & 65.548 & & \\
Total & 1717741.000 & 350 & & & \\
Corrected Total & 23537.569 & 349 & & & \\
\hline
\end{tabular}

$* *$ a. R Squared $=.048$ (Adjusted R Squared $=.028$ )

The As shown in Table 14 there were a no statistically significant differences between the mean values according to the gender variable $\mathrm{F}(7,1)=2.836, \mathrm{P}=\mathrm{P}=0.092$, there was no statistically significant differences between the mean values according to the faculty variable $\mathrm{F}(7,1)=0.001, \mathrm{P}=0.971$, and there was no statistically significant differences between the mean values according to the academic level variable $\mathrm{F}(7,1)=3.238, \mathrm{P}=0.0731$. depending on the significance of the calculated values of (F) shown in the previous table at the significance level $(\alpha \leq 0.05)$

\section{Discussion}

This study results showed that PSAU students have a moderate psychological well-being; self-efficacy and positive thinking level in general. these levels were positively related, which means high level of psychological well-being will directly increase self-efficacy and positive thinking. These results consistent are with the studies of (Santos,2014;Ersoz,2017; Tommasi,2018;Yuksel.et.al,2019) which founded that there is a strong relationship between psychological well-being and self-efficacy. Furthermore, the study of (Ghodsbin et al.,2015) found a strong relationship between psychological well-being and positive thinking. In addition, there was a positive correlation between self-efficacy and positive thinking, these results consistent with the study of (Caprara et al.,2006) which found that a high self- efficacy is related to high positive thinking, while low self-efficacy related to lower positive thinking. All the referenced studies are in support of the results.

In this study, results showed that there were no statistically significant differences between the mean values of the responses of the university's students in all the three independent variables according to (gender or faculty or academic level). These results differ from previous studies results such as (Siddiqui,2015; santos,2014) where it was founded that males have a higher level of psychological well-being than females and gender ,age had a strong impact on psychological well-being and self -efficacy, but Siddiqui found no effect for gender on psychological well-being ,just for self- Efficacy. However, a statistically significant differences were found between the mean values of the responses for self- efficacy according to the academic level variable, the differences were in favor of the master degree students group. Consequently, that bachelor students have a lower level of self -efficacy than their master degree counterparts, this result may be consistent with the studies (Fernandez,2019; Yuksel.et.al,2019) they found that self- efficacy is associated with age, the older individual has ahigh self-efficacy than younger ones.

Due to the difficulty in direct contacting with male students which influence the variety of the sample (73 males -277 females) the high number of female students affected the results in all the three independent variables. Other limitation can be the non-mixed colleges in the university, in addition to the physical separation of colleges in the university, which made reaching the sample members very difficult even electronically.

Moreover, the distribution of the sample members on demographic variables had the greatest impact on the progress of the results, the available sample was mostly females, Humanities Colleges, and bachelor's programs. This resulted in reducing the effect for demographic aspect on all the three main variables. 


\section{Conclusion}

On the basis of these finding it can be concluded that psychological Well-being has its positive and significant impact on self-efficacy and positive thinking among university students, and it was also found that self-efficacy and positive thinking enhance the psychological well-being. Consequently, if self-efficacy or positive thinking is low psychological well-being also low, if self-efficacy or positive thinking is high psychological well-being also high. Gender, academic level, faculty has no impact on psychological well-being or positive thinking except academic level on self -efficacy.

The accumulation of knowledge should be helpful for giving an idea to those in charge of university programs to identify the factors that significantly affect raising the level of positive thinking and self-efficacy among students to help them achieve their future aspirations in understanding university students, underlying psychological factors. The study was limited to university students and it used only quantitative methods to examine psychological well-being, self-efficacy and positive thinking.

Future studies are needed to use training programmers and different statistical analyses in order to draw conclusions for the potential link between psychological well-being aspects to other variables.

\section{Acknowledgment}

This research was supported by the Deanship of Scientific Research at Prince Sattam Bin Abdulaziz University (under the research project 2019/2/11259).

\section{References}

Abo-salama. M. (2014). The effectiveness of a training program in reducing psychological disturbance and social anxiety and its effect on self-efficacy, social competence and emotional equilibrium among high school students. unpublished Ph.D. thesis, Arab Research and Studies Institute, Arab Organization for Education, Culture and Science. Cairo. Egypt.

Aljaser. A. (2007). Emotional intelligence and its relationship to both self-efficacy and awareness of parental acceptance and rejection among a sample of male and female students from Umm Al-Qura University, unpublished master's thesis. Mecca. Saudi Arabia

AL-Hazmi. N. (2016). The global structure of psychological well-being for Umm Al-Qura University students, Unpublished Master Thesis, Umm Al-Qura University. Saudi Arabia.

Bekhet, A. K. \& Zauszniewski, J. A. (2013). Measuring use of positive thinking skills: Psychometric testing of a new scale. Western Journal of Nursing Research, 35(8), 1074-1093. https://doi.org/10.1177/0193945913482191

Bandura, A. (1994). Self-efficacy. In. VS Ramachandran. Encyclopedia of human behavior, 4(4), 71-81.

Bandura, A., Freeman, W. H. \& Lightsey, R. (1999). Self-efficacy: The exercise of control.

Bandura, A., Pastorelli, C., Barbaranelli, C. \& Caprara, G. V. (1999). Self-efficacy pathways to childhood depression. Journal of Personality and social Psychology, 76(2), 258. https://doi.org/10.1037/0022-3514.76.2.258

Bandura, A., Caprara, G. V., Barbaranelli, C., Gerbino, M. \& Pastorelli, C. (2003). Role of affective self-regulatory efficacy in diverse spheres of psychosocial functioning. Child development, 74(3), 769-782. https://doi.org/10.1111/1467-8624.00567

Bandura, A. (2012). On the functional properties of perceived self-efficacy revisited. 9-44. https://doi.org/10.1177/0149206311410606

Barlow, J., Wright, C. \& Cullen, L. (2002). A job-seeking self-efficacy scale for people with physical disabilities: Preliminary development and psychometric testing. British Journal of Guidance and Counselling, 30(1), 37-53. https://doi.org/10.1080/030698880220106500

Bisschop, M. I., Kriegsman, D. M., Beekman, A. T. \& Deeg, D. J. (2004). Chronic diseases and depression: the modifying role of psychosocial resources. Social science \& medicine, 59(4), 721-733. https://doi.org/10.1016/j.socimed.2003.11.038

Caprara, G. V., Steca, P., Gerbino, M., Paciello, M. \& Vecchio, G. M. (2006). Looking for adolescents' well-being: Self-efficacy beliefs as determinants of positive thinking and happiness. Epidemiology and Psychiatric Sciences, 15(1), 30-43. https://doi.org/10.1017/s1121189x00002013

Çakar, F. S. (2012). The Relationship between the Self-Efficacy and Life Satisfaction of Young Adults. International Education Studies, 5(6), 123-130. https://doi.org/10.5539/ies.v5n6p123 
Çardak, M. (2013). The relationship between forgiveness and humility: A case study for university students. Educational Research and Reviews, 8(8), 425. https://doi.org/10.5897/ERR2012.1071

Çelik, İ. \& Sarıçam, H. (2018). The relationships between academic locus of control, positive thinking skills and grit in high school students. Universal Journal of Educational Research, 6(3), 392-398. https://doi.org/10.13189/ujer.2018.060305

Dwiwardani, C., Hill, P. C., Bollinger, R. A., Marks, L. E., Steele, J. R., Doolin, H. N. \& Davis, D. E. (2014). Virtues develop from a secure base: Attachment and resilience as predictors of humility, gratitude, and forgiveness. Journal of Psychology and Theology, 42(1), 83-90. https://doi.org/10.1177/009164711404200109

Ersöz, G. (2017). The role of university students' general self-efficacy, depression and psychological well-being in predicting their exercise behavior. Journal of Education and Training Studies, 5(3), 110-117. https://doi.org/10.11114/jets.v5i3.2209

Faure, S. \& Loxton, H. (2003). Anxiety, depression and self-efficacy levels of women undergoing first trimester abortion. South African Journal of Psychology, 33(1), 28-38. https://doi.org/10.1177/008124630303300104

Fernández. M; Padilla .M; Nunes. C \& Menéndez, S. (2019). Psychological well-being in non-dependent active elderly individuals and its relationship with self-esteem and self-efficacy. Ciencia \& saude coletiva, 24(1), 115-124. https://doi.org/10.1590/1413-81232018241.35302016

İşgör, İ. Y. (2016). Metacognitive skills, academic success and exam anxiety as the predictors of psychological well-being. Journal of Education and Training Studies, 4(9), 35-42. https://doi.org/10.11114/jets.v4i9.1607

Ghodsbin, F., Safaei, M., Jahanbin, I., Ostovan, M. A. \& Keshvarzi, S. (2015). The effect of positive thinking training on the level of spiritual well-being among the patients with coronary artery diseases referred to Imam Reza specialty and subspecialty clinic in Shiraz, Iran: A randomized controlled clinical trial. ARYA atherosclerosis, 11(6), 41. https://doi.org/10.31838/ijpr/2020.12.01.022

Gómez-Baya, D., Lucia-Casademunt, A. M. \& Salinas-Pérez, J. A. (2018). Gender differences in psychological well-being and health problems among European health professionals: Analysis of psychological basic needs and job satisfaction. International journal of environmental research and public health, 15(7), 1474. https://doi.org/10.3390/ijerph15071474

Gregg, N. (2009). Adolescents and adults with learning disabilities and ADHD: Assessment and accommodation. New York, NY: Guilford.

Kashdan, T. B. \& Roberts, J. E. (2004). Trait and state curiosity in the genesis of intimacy: Differentiation from related constructs. Journal of Social and Clinical Psychology, 23(6), 792-816. https://doi.org/10.1521/jscp.23.6.792.54800

Kuijer, R. G. \& De Ridder, D. T. (2003). Discrepancy in illness-related goals and quality of life in chronically ill patients: the role of self-efficacy. Psychology and Health, 18(3), 313-330. https://doi.org/10.1080/0887044031000146815

Naseem, Z. \& Khalid, R. (2010). Positive Thinking in Coping with Stress and Health outcomes: Literature Review. Journal of Research \& Reflections in Education (JRRE), 4(1).

Radi.Z, Miteb.Z(2017). Positive thinking in college student, A master degree thesis, not published, king Abdul -Aziz university. Saudi Arabia.

Rasool, I., Zubair, A. \& Anwar, M. (2019). Role of Perceived Self-efficacy and Spousal Support in Psychological Well-being of Female Entrepreneurs. Pakistan Journal of Psychological Research, 34(4). https://doi.org/10.33824/pjpr.2019.34.4.48

Roothman, B., Kirsten, D. K. \& Wissing, M. P. (2003). Gender differences in aspects of psychological well-being. South African journal of psychology, 33(4), 212-218. https://doi.org/10.1177/008124630303300403

Ryff, C. D., Magee, W. J., Kling, K. C. \& Wing, E. H. (1999). Forging macro-micro linkages in the study of psychological well-being. The self and society in aging processes, 247-278. https://doi.org/10.1353/chapter.1483299

Ryff, C. D. \& Singer, B. H. (2008). Know thyself and become what you are: A eudaimonic approach to psychological well-being. Journal of happiness studies, 9(1), 13-39. https://doi.org/10.1007/978-94-007-5702-8_6 
Santos, M. C. J., Magramo Jr, C., Oguan Jr, F., Paat, J. J. \& Barnachea, E. A. (2012). Meaning in life and subjective well-being: is a satisfying life meaningful? Researchers World, 3(4), 32.

Santos, M. C. J., Magramo Jr, C. S., Oguan Jr, F. \& Paat, J. J. (2014). Establishing the relationship between general self-efficacy and subjective well-being among college students. Asian journal of management sciences \& education, 3(1), 1-12.

Seligman, M. E. (2002). Positive psychology, positive prevention, and positive therapy. Handbook of positive psychology, 2(2002), 3-12.

Sezgin, F. \& Erdogan, O. (2018). Humility and Forgiveness as Predictors of Teacher Self-Efficacy. Educational Research and Reviews, 13(4), 120-128. https://doi.org/10.5897/err2017.3449

Siddiqui, S. (2015). Impact of self-efficacy on psychological well-being among undergraduate students. The International Journal of Indian Psychology, 2(3), 5-16.

Tommasi, M., Grassi, P., Balsamo, M., Picconi, L., Furnham, A. \& Saggino, A. (2018). Correlations between personality, affective and filial self-efficacy beliefs, and psychological well-beingin a sample of Italian adolescents. Psychological reports, 121(1), 59-78. https://doi.org/10.1177/0033294117720698

Tugade, M. M. \& Fredrickson, B. L. (2004). Resilient individuals use positive emotions to bounce back from negative emotional experiences. Journal of personality and social psychology, 86(2), 320. https://doi.org/10.1037/0022-3514.86.2.320

Yuksel, A. \& Bayrakci, H. (2019). Self-efficacy, Psychological Well-Being and Perceived Social Support Levels in Pregnant Women. International Journal of Caring Sciences, 12(2), 1-10.

Zaker, A., Dadsetan, A., Nasiri, Z., Azimi, S. \& Rahnama, F. (2016). Effectiveness of Happiness on Self-efficacy of Students. Electronic Journal of Biology, 12(4), 26-32.

Zeldin, A. L., Britner, S. L. \& Pajares, F. (2008). A comparative study of the self-efficacy beliefs of successful men and women in mathematics, science, and technology careers. Journal of Research in Science Teaching: The Official Journal of the National Association for Research in Science Teaching, 45(9), 1036-1058. https://doi.org/10.1002/tea.20195 